\title{
Decreased frontal activation in schizophrenics during stimulation with the Continuous Performance Test - a functional magnetic resonance imaging study
}

\author{
H.-P. Volz ${ }^{1}$, C. Gaser ${ }^{1}$, F. Häger ${ }^{1}$, R. Rzanny², J. Pönisch ${ }^{1}$, H.-J. Mentzel², \\ W.A. Kaiser ${ }^{2}$, H. Sauer ${ }^{1}$ \\ ${ }^{1}$ Department of Psychiatry; 2 Institute of Diagnostical and Interventional Radiology (IDIR), Friedrich-Schiller- \\ University Jena, Germany
}

\begin{abstract}
Summary - The Continuous Performance Test (CPT) has become an essential constituent of the neuropsychological investigation of schizophrenia. Also, a vast number of brain imaging studies, mostly PET investigations, have employed the CPT as a cognitive challenge and established a relative hypofrontality in schizophrenics compared to controls. The aim of the present investigation was to clarify whether this predescribed hypofrontality could also be verified using functional magnetic resonance imaging (fMRI). 20 healthy volunteers and 14 schizophrenics on stable neuroleptic medication were included. Imaging was performed using the CPT-double-T-version and a clinical 1.5 T MRI-scanner with a single slice technique and a $\mathrm{T}_{2}{ }^{*}$-weighted gradient-echo-sequence. The schizophrenics exhibited a decreased activation in the right mesial prefrontal cortex, the right cingulate and the left thalamus compared to controls. These results obtained by fMRI are discussed in relation to published findings using PET. ( ) Elsevier, Paris
\end{abstract}

functional magnetic resonance imaging / schizophrenia / attention / hypofrontality

\section{INTRODUCTION}

One major finding of functional brain imaging studies in schizophrenia is hypofrontality $[4,51]$. This finding is inconsistent when patients are investigated at rest, some studies even demonstrated an increased activity in the frontal lobe especially when acute, neuroleptic free patients [15] were studied. Cognitive challenges more or less specific for frontal lobe functions increase the likelihood to detect hypofrontality. The most widely used tests to demonstrate this "behaviour-specific" hypofrontality are the Wisconsin Card Sorting Test (WCST), involving working memory and the ability to adapt behaviour based on performance feedback [30, 49], the Raven Progressive Matrices, which tap the ability to perceive sequential non-verbal abstract patterns [7, 27, 41], and the Continuous Performance Test (CPT).
As animal studies suggest [31] attention requires the integrity of cingulate, thalamic, inferior parietal and prefrontal cortical function, with right hemisphere structures playing a more prominent role than left. The CPT appears to recruit sustained attention [8, 10, 42] and has therefore become a virtual landmark task in the cognitive study of schizophrenia [48], exhibiting impaired performance not only in schizophrenia itself, but also in schizophrenia spectrum disorders and in unaffected relatives of patients [35]. Beside neuropsychological investigations, several brain imaging studies with the CPT comparing schizophrenics with controls have also been performed. The methods used were single photon emission tomography (SPECT) with the xenon inhalation technique [8] or positron emission tomography (PET) using ${ }^{18} \mathrm{~F}$ labelled glucose $\left({ }^{18} \mathrm{FDG}\right)$ as a tracer $[12-14,16,19,29,43-46]$. The most consistent results of these investigations were decreased 
activation in the frontal cortex and the cingulum in schizophrenics compared to controls.

In recent years, functional magnetic resonance imaging (fMRI), a new brain imaging method, has been developed. The principle is based on the different behaviour of oxygenated and deoxygenated haemoglobin $\left(\mathrm{HbO}_{2}\right.$ and $\left.\mathrm{deHbO}_{2}\right)$ in the magnetic field [26]. As $\mathrm{deHbO}_{2}$ is used as an intrinsic contrast agent, the application of radioactive-labelled compounds is no longer necessary. Depending on the field of view, a resolution of up to $1 \mathrm{~mm}$ is possible, which overcomes the restricted spatial resolution of SPECT and also PET. A further advantage consists of the simultaneous acquisition of activation and topographical data. An overlap of two completely independent measures, as required in the case of SPECT and PET, is no longer necessary. To our knowledge, only two fMRI-studies using fMRI and the CPT in healthy volunteers are published $[5,16]$.

The present study was designed to focus on two main questions: i) is it possible to replicate the predescribed activation differences of schizophrenics and controls obtained primarily with ${ }^{18}$ FDG-PET using fMRI?, and ii) can the underlying anatomical structures of the activation deficit be determined more precisely? Beside these issues, special attention was applied to the performance of the probands in order to reduce potentially confounding motivational effects during the performance of the stimulation task.

\section{METHODS}

\section{Subjects}

All subjects (healthy controls and patients) were righthanded [36]. Written informed consent was obtained, all probands were native German speakers and not paid for their participation. All participants were screened thoroughly for internal and neurological symptoms, persons exhibiting such symptoms or with first degree relatives showing severe neurological disorders were excluded. A history or presence of alcohol or drug abuse was a further exclusion criterion.

A total of 20 healthy controls (12 males, eight females) with a mean age of 28.2 years (standard deviation [SD]: 5.7), recruited by advertisement, were included. They had to be free from any psychotropic or cardiovascular medication. The volunteers were thoroughly screened for psychiatric illnesses, persons show- ing any symptoms or with first degree relatives suffering from psychiatric disorders were excluded.

Fourteen schizophrenic inpatients $(11$ males, three females), mean age 34.1 years (SD: 12.29) diagnosed according to DSM III-R [1] were investigated. The patients had to by free of drugs but were on stable neuroleptic medication (10 $\mathrm{mg}$ haloperidol or equivalent; mean chlorpromazine equivalent dose: 652 [668] mg). Psychopathology was rated using the Brief Psychiatric Rating Scale (BPRS [37]), the Clinical Global Impression (CGI [32]), the Scale for the Assessment of Negative Symptoms (SANS [2]), and the Scale for the Assessment of Positive Symptoms (SAPS [3]). The mean psychopathological rating scale scores were: CGI: 4.4 (SD: 1.5), BPRS: 42.5 (SD: 8.7), SANS: 43.1 (SD: 14.2), SAPS: 15.6 (SD: 8.2). The psychopathological ratings were performed by two experienced psychiatrists (HPV, FH) with an interrater reliability > 0.9.

The study was approved by the ethical review board of the University of Jena.

\section{Stimulation and performance}

For stimulation we used the Stim ${ }^{\circledR}$ PC-version of the CPT [33] and projected the material via a Philips LC 2000 projector on a screen placed in front of the MRI scanner. By means of an angled mirror, placed above the head coil, the screen became visible for the participant. The subjects responded with their right hand using a hydropneumatic tap-device. The ears were plugged with wax to reduce the noise level in the scanner. On the day before the fMRI measurement, a learning session of $15 \mathrm{~min}$ took place during which the probands were familiarised with the whole test procedure.

The CPT-double-T-version was used. Subjects were asked to press a button as fast as possible when a "T" was followed by another " $T$ ". Each stimulus block consisted of 36 targets, 18 distracters and 126 nontargets in a pseudo-random order. Target probability was $25 \%$, the interstimulus interval $1.2 \mathrm{~s}$, stimulus exposure time $0.6 \mathrm{~s}$. All subjects performed the task four times.

Each series began with one image at rest (31 s) allowing MRI signal equilibrium to be reached, followed by 40 images alternating baseline condition (eyes open, tapping the response device in a freely chosen rhythm) and activation every $2: 35 \mathrm{~min}$ (5:10 min per cycle, ten images per cycle, four cycles). The total duration was about $30 \mathrm{~min}$. 
Subjects' performance in the CPT can be evaluated in various ways. We used errors of omission and commission (hit-rate and false alarm-rate), mean response latency, $\mathrm{d}^{\prime}$ as a measurement for discriminability and $\ln$ $\mathrm{b}$ as the so-called response criterion $[20,24,34]$. The signal detection index $\mathrm{d}^{\prime}$ (sensitivity) is a parameter that characterises the ability to discriminate target and non-target stimuli. So, a subject with a high sensitivity shows a high hit rate (ie, few errors of omission) and a low false alarm rate (few errors of commission). The so-called response criterion $\ln b$ measures the amount of perceptual evidence that the subject requires to decide whether a stimulus is a target or not. So, a subject with a 'cautious' response criterion has a low target hit rate and a low false alarm rate in contrast to more 'liberal' subjects. Both groups were retrospectively divided into good (no commission errors) and poor (at least one commission error) performers based on their performance data sampled on-line during fMRI.

\section{Scanning procedures}

Imaging was performed on a 1.5 Tesla (Philips Gyroscan ACSII) MR tomograph using a standard head coil. For functional imaging, a $\mathrm{T}_{2}{ }^{*}$-weighted gradient-echosequence (FFE) was used (echo time: $50 \mathrm{~ms}$, repetition time: $100 \mathrm{~ms}$, field of view: $230 \mathrm{~mm}$, matrix: $256 \times$ 256, slice thickness: $10 \mathrm{~mm}$, voxel dimension: $0.9 \times 0.9$ $\times 10 \mathrm{~mm}^{3}$, flip angle: $40^{\circ}$ ). Scanning also included acquisition of high-resolution anatomical images for localisation purposes ( $\mathrm{T}_{1}$-weighted, echo-time: $15 \mathrm{~ms}$, repetition time: $300 \mathrm{~ms}$, field of view: $230 \mathrm{~mm}$, matrix: $256 \times 256$, slice thickness: $3 \mathrm{~mm}$ ), localised in the same plane and centre position as the $\mathrm{T}_{2}{ }^{*}$-weighted images.

In order to ensure that in different subjects the same region was measured, the following procedure was used: a series of scout images (an initial set of five sagittal, transversal and coronal slices) was acquired, followed by a series of sagittal slices parallel to the brain's true midline. In the midline plane, the straight line between the commissura anterior and posterior (AC-PC line) was used to determine orientation and localisation of the plane used for functional imaging. The crossing points of a perpendicular to the AC-PCline through $\mathrm{AC}$ with the cerebral surface and of the AC-PC-line with the cerebral surface were identified. A line parallel to these two reference points crossing PC determined the slice where our fMRI measurement took place (figure 1). The described procedure ensures

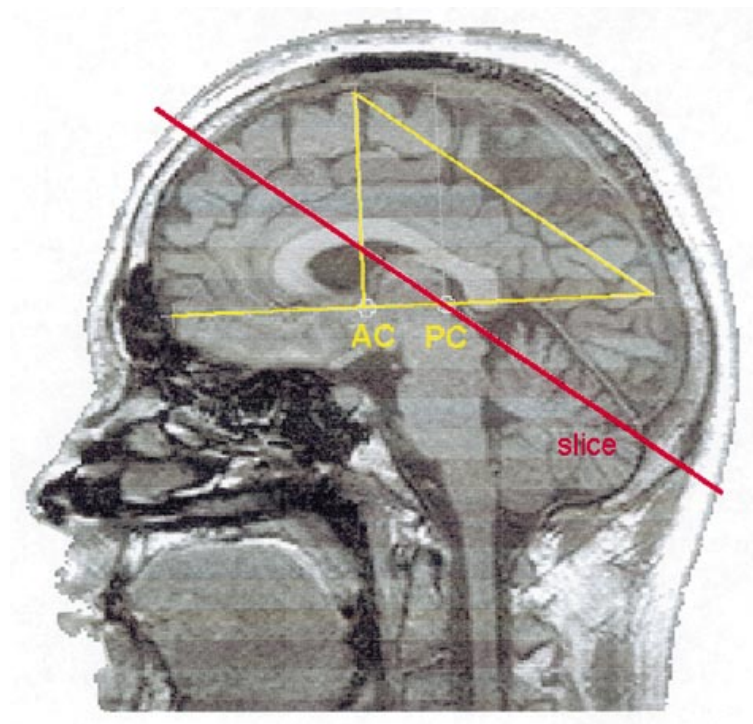

Figure 1. Slice planning.

( $T_{1}$-weighted echo-time: $15 \mathrm{msec}$, repetition time: $300 \mathrm{msec}$, field of view: $230 \mathrm{~mm}$, matrix 256X256, slice thickness: $10 \mathrm{~mm}$ ). In order to reliably define the measured slice, the commissura anterior (AC) and posterior (PC) was defined in the midline plane of the scout images. The crossing point of a perpendicular to the AC-PC-line with the cerebral surface were identified. A line parallel to these two reference points crossing PC determined the slice where fMRI measurement took place.

that scan orientation and localisation are highly reliable across sessions and across individuals.

In order to facilitate spatial orientation, the measured slice was transformed into the Talairach space [47], so that also the Talairach co-ordinates of activations could be obtained (figure 2).

This single $10 \mathrm{~mm}$ slice covers frontal lobe, cingulum, thalamus, caudate nucleus, hippocampus, temporal lobe and cerebellum. However, no activation data of regions outside this slice can be obtained.

\section{Image analysis}

The image data were analysed with SPM96 (statistical parametric mapping [22]) implemented in Matlab. To remove movement-related variance components in the time series the scans were realigned to the first scan which was checked for the absence of motion artefacts. Three parameters (rotation, translation $\mathrm{x}$ and $\mathrm{y}$ ) were estimated using a least squares analysis [21]. Subjects whose images exhibited a translation of $\geq 2 \mathrm{~mm}$ or a rotation of $\geq 2^{\circ}$ were not included in the study. In order 


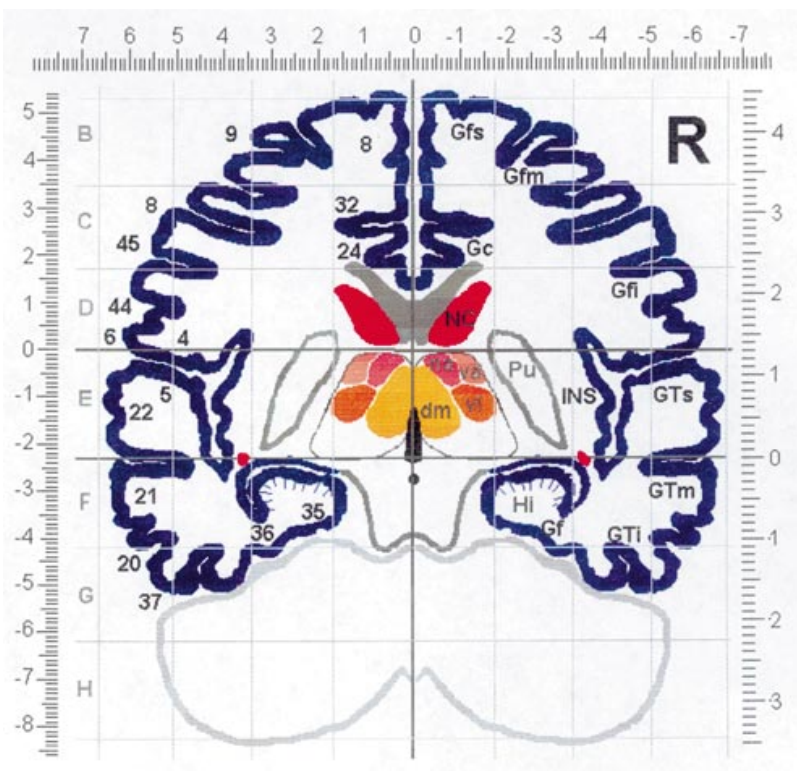

Figure 2. Projection of the slice of measurement within the Talairach space.

The respective Talairach coordinates are also given according to Talairach and Tournoux (1988); top x-axis, left y-axis (+ 3 units), right z-axis (+ 4 units). Deviations for the $y$-and z-axis are due to the oblique slice orientation. The transformation was done manually based on the standard Talairach brain. The numbers on the left side indicate the respective Brodmann-areas.

(Abbreviations: $\mathrm{dm}=$ nucleus dorsomedialis thalami, $\mathrm{Gc}=$ gyrus cinguli, Gfi=gyrus frontalis inferior, Gfm=gyrus frontalis medius, Gfs=gyrus frontalis superior, GTi=gyrus temporalis inferior, $\mathrm{GTm}=$ gyrus temporalis medius, GTs=gyrus temporalis superior, $\mathrm{Hi}=$ hippocampus, INS=insula, $\mathrm{Na}=$ nucleus anterior thalami, $\mathrm{NC}=$ nucleus caudatus, $\mathrm{Pu}=$ putamen, $\mathrm{va}=$ nucleus ventralis anterior thalami, $v l=$ nucleus ventralis lateralis thalami).

to spatially normalise the images and thus facilitating intersubject averaging the data from different subjects had to be transformed into a standard anatomical space. Six parameters of a two-dimensional affine transformation (rotation, translation $\mathrm{x}$ and $\mathrm{y}$, zoom $\mathrm{x}$ and $\mathrm{y}$, shear) were estimated to normalise the data to a predefined template [21]. The used mean motion correction per image in the x-direction was 0.35 (SD: 0.17 ) $\mathrm{mm}$ for controls and 0.50 (SD: 0.27$) \mathrm{mm}$ for schizophrenics, in the y-direction 0.55 (SD: 0.25) mm resp. 0.92 (SD: $0.77) \mathrm{mm}$, for the rotation 0.42 (SD: 0.22$)^{\circ}$, resp. 0.78 (SD: 0.61$)^{\circ}$. So, the amount of motion correction necessary was higher in the schizophrenics, but overall rather moderate. This procedure was followed by a spatial smoothing using an isotropic Gaussian kernel. The reason for smoothing is to increase the signal relative to noise, to condition the data in the sense that the data conform more closely to a Gaussian field model and to facilitate intersubject averaging. For multisubject analysis a FWHM of $6 \mathrm{~mm}$ was used. To keep the better spatial resolution of single subject analysis, a smaller FWHM of $4 \mathrm{~mm}$ was applied in this case.

The data were analysed with SPM96 using analysis of covariance (ANCOVA) with global activity as a subject specific confounding covariate [21,23]. For single subject analysis a simple subtractive design (on vs. off) was performed. The differences in activations between schizophrenics and controls were assessed using a factorial design with a group $\mathrm{x}$ condition interaction.

\section{RESULTS}

\section{Cpt-performance}

The performance parameters of controls and schizophrenics are given in table $I$.

Table I. CPT-performance of controls $(C)$ and schizophrenics $(S)$. Beside the values for the whole groups, also the parameters of the male good (GP) and male poor performers (PP) are given. Standard deviation in brackets.

\begin{tabular}{|c|c|c|c|c|c|c|}
\hline & $\begin{array}{c}C \\
(n=20)\end{array}$ & $\begin{array}{c}S \\
(n=14)\end{array}$ & $\begin{array}{c}\text { male } C, G P \\
\quad(n=5)\end{array}$ & $\begin{array}{c}\text { male } S, G P \\
\quad(n=5)\end{array}$ & $\begin{array}{c}\text { male } C, P P \\
\quad(n=7)\end{array}$ & $\begin{array}{c}\text { male } S, P P \\
\quad(n=6)\end{array}$ \\
\hline Hit-rate & $\begin{array}{c}0.89 \\
(0.14)\end{array}$ & $\begin{array}{c}0.92 \\
(0.08)\end{array}$ & $\begin{array}{c}0.98 \\
(0.03)\end{array}$ & $\begin{array}{c}0.97 \\
(0.04)\end{array}$ & $\begin{array}{c}0.85 \\
(0.16)\end{array}$ & $\begin{array}{c}0.91 \\
(0.06)\end{array}$ \\
\hline False alarm rate & $\begin{array}{c}0.01 \\
(0.01)\end{array}$ & $\begin{array}{c}0.02 \\
(0.02)\end{array}$ & $\begin{array}{c}0 \\
(0)\end{array}$ & $\begin{array}{c}0 \\
(0)\end{array}$ & $\begin{array}{c}0.02 \\
(0.01)\end{array}$ & $\begin{array}{c}0.02 \\
(0.01)\end{array}$ \\
\hline Mean response latency $[\mathrm{s}]$ & $\begin{array}{c}0.42 \\
(0.20)\end{array}$ & $\begin{array}{c}0.44 \\
(0.08)\end{array}$ & $\begin{array}{c}0.39 \\
(0.07)\end{array}$ & $\begin{array}{c}0.43 \\
(0.07)\end{array}$ & $\begin{array}{c}0.39 \\
(0.01)\end{array}$ & $\begin{array}{c}0.46 \\
(0.10)\end{array}$ \\
\hline $\mathrm{d}^{\prime}$ & $\begin{array}{c}4.23 \\
(0.91)\end{array}$ & $\begin{array}{c}3.98 \\
(0.92)\end{array}$ & $\begin{array}{c}5.16 \\
(0.23)\end{array}$ & $\begin{array}{c}4.88 \\
(0.58)\end{array}$ & $\begin{array}{c}3.57 \\
(0.72)\end{array}$ & $\begin{array}{c}3.65 \\
(0.53)\end{array}$ \\
\hline $\ln b$ & $\begin{array}{c}2.73 \\
(1.38)\end{array}$ & $\begin{array}{c}2.07 \\
(0.94) \\
\end{array}$ & $\begin{array}{c}3.27 \\
(0.37)\end{array}$ & $\begin{array}{c}3.10 \\
(0.60) \\
\end{array}$ & $\begin{array}{c}1.89 \\
(1.57) \\
\end{array}$ & $\begin{array}{c}1.63 \\
(0.24)\end{array}$ \\
\hline
\end{tabular}




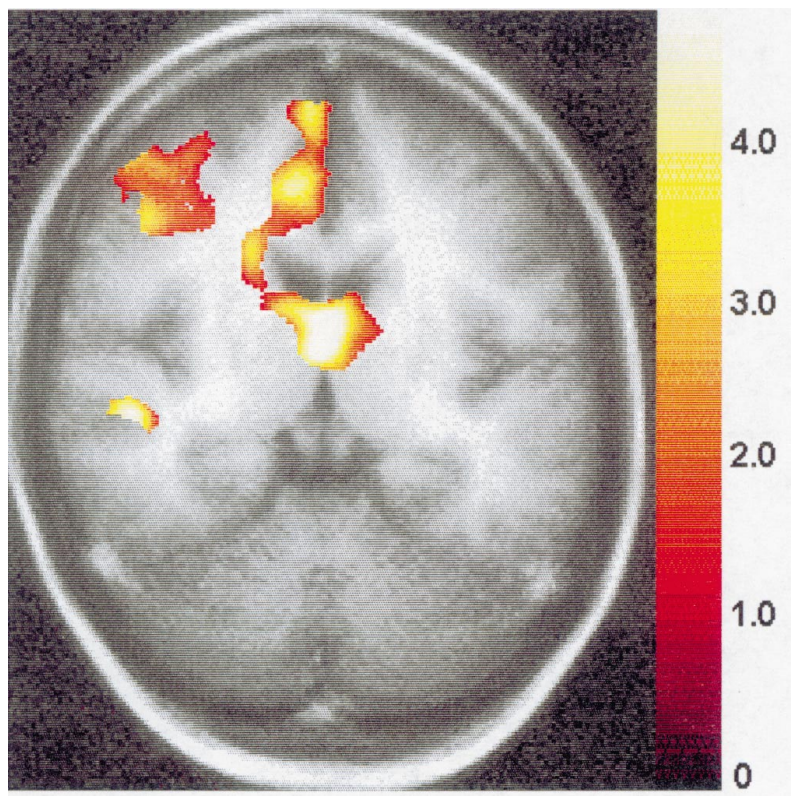

Figure 3. Controls-whole group $(\mathrm{N}=20)$.

Statistical parametric map (SPM $\{Z\})$. The underlying slice is the average of all individual anatomical slices $(N=20)$ with the orientation described above. Data are presented for clusters and regions that survived the heigth and extent threshold detailed in the method section of the paper. The color scale is arbitrary, red and yellow represent the respective Z-values.

In the following fig. 4 the same color coding is used.

Both groups exhibited very similar test performance. For further analysis, the female probands were excluded, the males were split into good and poor performers. The respective values are also given in table I.

\section{Activation - controls}

Activations in a variety of cortical and subcortical regions were detected. The entire control group $(n=20$, figure 3) exhibited activations in the right dorsolateral and mesial prefrontal cortex, in the right cingulate, in the right caudate, in thalamic nuclei bilaterally (especially antero-ventral $\mathrm{ncl}$ ), and, to a smaller extent, in the right superior temporal gyrus.

In order to obtain information about the influence of CPT-performance on the activation pattern, the male $(\mathrm{n}=12)$ probands were split into good $(\mathrm{n}=5)$ and poor $(n=7)$ performers according to the criterion specified under 'methods'. Only males were included into this analysis since we observed pronounced gender effects in a detailed analysis of the healthy volunteers [25]. Over-

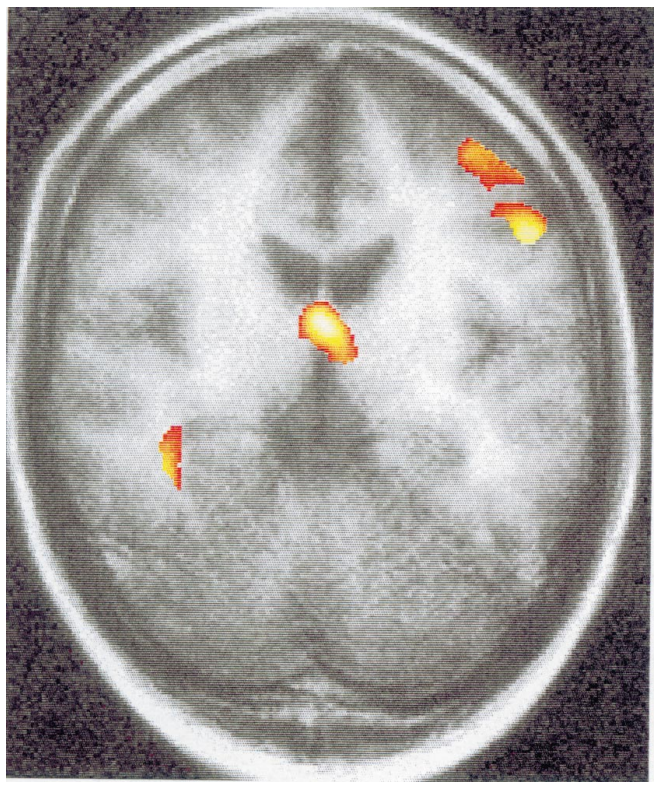

Figure 4. Schizophrenics-whole group $(\mathrm{N}=14)$.

all, poor performers activated more brain regions compared to good performers, this difference being statistically significant in the right dorsolateral prefrontal cortex.

\section{Activation - schizophrenics}

The whole group of schizophrenics exhibited a quite different activation pattern compared to controls. The right prefrontal activation (comprising both the right dorsolateral and mesial prefrontal cortex) was missing as well as the activation in the cingulate and in the caudate (see figure 4). For the difference image (schizophrenics vs. controls), the missing activation in the right mesial prefrontal cortex and the cingulate as well as the left antero-ventral nucleus of the thalamus reached statistical significance (see figure 5).

In analogy to the controls, the male schizophrenics $(\mathrm{n}=11)$ were further subdivided into $\operatorname{good}(\mathrm{n}=5)$ and poor $(n=6)$ performers. Whereas there were no major additional group differences for the good performers between controls and schizophrenics it became obvious that the poor male schizophrenic performers activated more than the poor male control performers in the right temporal lobe and less in the left dorsolateral prefrontal cortex. 


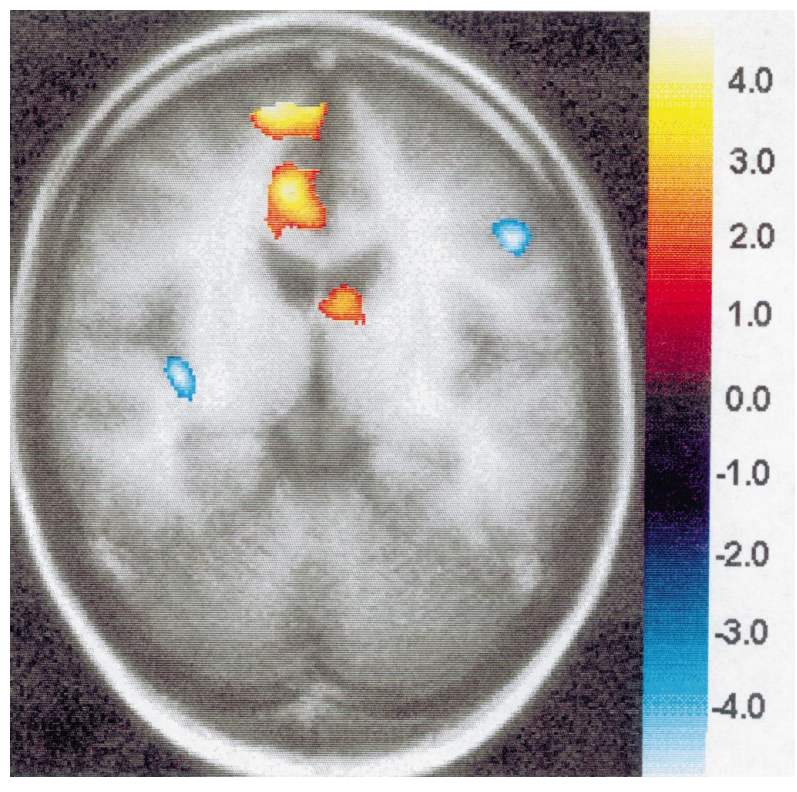

Figure 5. Interaction group $x$ condition.

Group 1 are the 20 control subjects, group 2 the 14 schizophrenics. Red areas indicate significantly increased activations in controls compared to schizophrenics, for blue areas it is vice versa.

\section{DISCUSSION}

The main finding or our study was that schizophrenics exhibited a decreased activation in the right mesial prefrontal cortex, the right cingulate and the left thalamus compared to controls with the CPT as a cognitive challenge and $\mathrm{fMRI}$ as the functional brain imaging method. These activation differences were not dependent of the performance in the CPT.

Before discussing the relation of these main results to prior functional imaging studies with the CPT, we want to comment on some methodological limitations of our study.

Before all, we used a single, $10 \mathrm{~mm}$ thick slice covering parts of the frontal lobe, the cingulum, the caudate nucleus, hippocampus, temporal lobe and cerebellum. With such a technique, it is only possible to obtain activation information about areas within this slice. It might well be that above or below this slice activations are considerably different. Since this study was performed with an MRI not equipped for EPI (echo planar imaging), it was not possible for us to measure the whole brain or multiple slices within a reasonable imaging time.

Another point of criticism might be the definition of the 'rest' condition which controlled only for motor activation and simple visual input. One might argue that all non-crucial elements of the CPT should have been included into this rest or control condition. However, the CPT is a typical example of a complex test procedure, e.g., the WCST, including elements such as feature and letter detection, focused attention, shortterm/working memory and vigilance. Up to now, it has not been shown which of these components is decisive for the different activation pattern in schizophrenics compared to controls. For this reason, we decided to include no additional elements into the control condition. In future studies, it is planned to test the different elements of the CPT separately.

Another item is whether short stimulation exposures as in our investigation (2:35 min) are sufficient to produce activation in response to the CPT. In former studies primarily performed by the group of Buchsbaum [11, $29,43,44,45,46]$ using ${ }^{18}$ FDG-PET, rather long stimulation periods (approximately $30 \mathrm{~min}$ ) were used, which is not feasible in fMRI-studies. However, since we found similar activation differences between schizophrenics and controls as described by the above mentioned authors, it can be assumed that short stimulation periods are also sufficient to produce reliable activation patterns. Besides, it is well shown that related challenges like the sequential letter task or spatial memory tasks elicit activation in fMRI-studies using very rapid alterations between stimulation and rest/control condition [9] (duration of stimulation: $75 \mathrm{~s}$ ). Moreover, the CPT has been shown to induce reasonable activation patterns using fMRI in healthy volunteers [5] (not reported); [16] (60 s); [25] (2:35 min).

A further limitation of this study is that all our patients were on neuroleptics when fMRI-measurement took place and, therefore, the demonstrated activation differences might only be due to that fact. Regarding this methodological limitation, we refer to the discussion of our results in comparison to previous work below.

The activation pattern of the control group is subject of another paper of our group [25] and will not be discussed further. In the present paper, we focus on the differences between schizophrenics and controls. One of our major results is that schizophrenics activated less than controls in the right mesial prefrontal cortex and the right cingulate. This result is in good accordance with the following reports using ${ }^{18}$ FDG-PET: Siegel et al ( [45]; CPT-visual, degraded version, [70] unmedicated schizophrenics), Siegel et al ( [46]; CPT-visual, degraded version, [25] unmedicated schizophrenics), and [11], CPT-visual, degraded version, [20] 
neuroleptic-naive schizophrenics). Also Schröder et al $[43,44]$ found decreased activations in schizophrenics for the mesial frontal cortex compared to controls. However, since most of the included patients were already part of other studies of the Buchsbaum-group, these two papers are not further included into the discussion of our results. So, regarding the mesial frontal cortex and the cingulum, our results replicate findings obtained by other functional brain imaging methods. Since these studies were performed either on unmedicated or even on neuroleptic-naive schizophrenic patients, a major influence of neuroleptics on the different activation pattern of schizophrenics and controls does not seem very probable. However, for the frontal cortex, two ${ }^{18}$ FDG-PET studies, using an auditory, not a visual CPT-version report that neuroleptics lower the activation $[17,19]$. It remains unclear whether visual and auditory CPT versions are subject to the same influence of neuroleptics.

Regarding the lowered activation in the left anteroventral thalamus in schizophrenics compared to controls, in one paper [14] using ${ }^{18}$ FDG-PET, a relatively decreased activation in the right thalamus was also described. When analysing the anterior part of the thalamus separately, this lowered activation was present bilaterally. In the recently published ${ }^{18}$ FDG-PETstudy of Katz et al [29] using correlation analyses between different brain areas in schizophrenics $(\mathrm{n}=18)$ and controls $(n=22)$ performing a visual CPT the largest difference in the correlations was present in those between the anterior thalamus and the frontal cortex, suggesting that this thalamic region plays a key role in the thalamo-cortico-striatal circuit suggested to be disturbed in some models of schizophrenia $[6,38$, $39,40]$. In a subgroup analysis of male schizophrenics versus male controls not reported in the result part of the paper, we found a decreased activation in the right caudatum of the patients. Thus, the third element of the hypothesised disturbed network, the striatum, was also found to be underactivated at least in a subgroup of the included patients. A similar deficit was prescribed bilaterally by Siegel et al [45] and left-lateralised by Buchsbaum et al [11]. Katz et al [29] link the dysfunction of the thalamo-cortico-striatal circuit to disturbed dopamine and glutamate transmission processes which might lead to impaired control of arousal and of the filtering of sensory input to the cortex via the thalamus.

So, some of the main anatomical structures of disturbed neural functioning in schizophrenics could be identified in our fMRI-study. However, by means of
fMRI it is not possible to obtain clear information on the location of the primary focus of disturbance, since this method, as PET and SPECT, is not able to reveal the time course of information transmission along neuronal pathways. Regarding this issue fast time methods with the possibility of deep structure identification as, e.g., magnetoencephalography, could be useful. On the other hand, it is questionable whether such a monofocal approach for explaining the found alterations in the schizophrenic group is valid. Keeping in mind the neurodevelopmental hypothesis of schizophrenia [28, $50]$, it might also be possible that the connections between the different brain areas are disturbed.

\section{REFERENCES}

1 American Psychiatric, Association . Diagnostic and statistical manual of mental disorders. Third Edition, revised. Washington: American Psychiatric Press; 1987.

2 Andreasen NC.The scale for the assessment of negative symptoms (SANS).Iowa: The University of Iowa; 1983.

3 Andreasen NC. The scale for the assessment of positive symptoms (SAPS).Iowa: The University of Iowa; 1984.

4 Andreasen NC, Rezai K, Swayze VW, Ii, FLAUM, M, KIRCHNER, P, COHEN, G et al Hypofrontality in neuroleptic naive patients and in patients with chronic schizophrenia. Assessment with xenon single-photon emission computed tomography and the Tower of London. Arch Gen Psychiatry 1992; 49 : 943-58.

5 Barch DM, Braver TS, Nystom L, Carter CS, Noll DC, Cohen $\mathrm{J}$. Activation of prefrontal cortex by context processing. Biol Psychiatry 1997; 41 : 85S.

6 Barnes TRE. Tardive dyskinesia: Risk factors, pathophysiology and treatment. In: Granville-Grossman K, Ed. Recent advances in clinical psychiatry, number six. London: Churchill Livingstone; 1988. p. 195205.

7 Berman KF, Illowsky BP, Weinberger DR. Physiological dysfunction of dorsolateral prefrontal cortex in schizophrenia. IV. Further evidence for regional and behavioral specifity. Arch Gen Psychiatry 1988; 45 : 616-22.

8 Berman KF, Zec RF, Weinberger DR. Physiological dysfunction of dorsolateral prefrontal cortex in schizophrenia. II: Role of neuroleptic treatment, attention and mental effort. Arch Gen Psychiatry 1986; $43:$ 125-35.

9 Braver TS, Cohen JD, Nystrom LE, Jonides J, Smith EE, Noll DC. A parametric study of prefrontal cortex involvement in human working memory. Neuroimage 1997; 5 : 49-62.

10 Buchsbaum MS. The frontal lobes, basal ganglia, and temporal lobes as sites for schizophrenia. Schizophr Bull 1990; 16 : 379-89.

11 Buchsbaum MS, Haier RJ, Potkin SG, Nuechterlein K, Bracha HS, Katz M et al Frontostriatal disorder of cerebral metabolism in never-medicated schizophrenics. Arch Gen Psychiatry 1992a; $49: 935-42$.

12 Buchsbaum MS, Nuechterlein KN, Haier RJ, Wu J, Sicotte N, Hazlett E et al Glucose metabolic rate in normals and schizophrenics during the Continuous Performance Test assessed by positron emission tomography. Brit J Psychiatry 1990; 156 : 216-27. 
13 Buchsbaum MS, Potkin SG, Siegel BV Jr, Lohr J, Katz M, Gottschalk LA et al Striatal metabolic rate and clinical response to neuroleptics in schizophrenia. Arch Gen Psychiatry 1992b; 49: 966-74.

14 Buchsbaum MS, Someya T, Teng CY, Abel L, Chin S, Najafi A et al PET and MRI of the thalamus in never medicated patients with schizophrenia. Am J Psychiatry 1996; 153 : 191-9.

15 Cleghorn JM, Garnett ES, Nahmias C, Firman G, Brown GM, Kaplan RD et al Increased frontal and reduced parietal glucose metabolism in acute untreated schizophrenia. Psychiatry Res 1989; $28: 119-33$.

16 Cohen JD, Forman SD, Braver TS, Casey BJ, Servan-Schreiber $\mathrm{D}$, Noll DC. Activation of the prefrontal cortex in a nonspatial working memory task with functional MRI. Human Brain Mapping 1994; 1 : 293-304.

17 Cohen RM, Nordahl TE, Semple WE, Andreason P, Litman RE, Pickar D. The brain metabolic patterns of clozapine- and fluphenazine-treated patients with schizophrenia during a continuous performance task. Arch Gen Psychiatry 1997; 54: 481-6.

18 Cohen RM, Semple WE, Gross M, Nordahl TE, Delisi LE, Holcomb $\mathrm{HH}$ et al Dysfunction in a prefrontal substrate of sustained attention in schizophrenia. Life Sciences 1987; 40 : 2031-9.

19 Cohen RM, Semple WE, Gross M, Nordahl TE, Holcomb $\mathrm{HH}$, Dowling MS et al The effect of neuroleptics on dysfunction in a prefrontal substrate of sustained attention in schizophrenia. Life Sciences 1988; 43 : 1141-50.

20 Egan JP. New York: Academic Press; 1980.

21 Friston KJ, Ashburner J, Frith CD, Poline JP, Heather JB, Frackowiak RSJ. Spatial registration and normalization of images. Human Brain Mapping 1995a; 2 : 165-89.

22 Friston KJ, Holmes AP, Worsley KJ, Poline JP, Frith CD, Frackowiak RSJ. Statistical parametric maps in functional imaging: A general linear approach. Human Brain Mapping 1995b; 2 : 189-210.

23 Friston KJ, Worsley KJ, Frackowiak RSJ, Maziotta JC, Evans AC. Assessing the significance of focal activations using their spatial extent. Human Brain Mapping 1994; 1 : 214-20.

24 Grier JB. Non parametric indices for sensitivity and bias: computing formulas. Psychol Bull 1971; 75 : 424-9.

25 Häger F, Volz HP, Gaser C, Mentzel HJ, Kaiser WA, Sauer H. Challenging the anterior attentional system with a continuous performance task - a functional magnetic resonance imaging approach. Eur Arch Neurol Psychiatry 1998; in press.

26 Himke RM, Hu X, Stillman AE, Kim SE, Merkle H, Salmi R et al Functional magnetic resonance imaging of Brocás area during internal speech. NeuroReport 1993; 4:675-8.

27 Ingvar DH, Franzen G. Abnormalities of cerebral blood flow distribution in patients with chronic schizophrenia. Acta Psychiatr Scand 1974; $50:$ 425-62.

28 Jones P, Murray RM. The genetics of schizophrenia is the genetics of neurodevelopment. Brit J Psychiatry 1991; 158 : 615-23.

29 Katz M, Buchsbaum MS, Siegel BV, Wu J, Haier RJ, Bunney WE. Correlational patterns of central glucose metabolism in never medicated schizophrenics. Neuropsychobiol 1996; 33 : $1-11$.

30 Marenco S, Coppola R, Daniel DG, Zigun JR, Weinberger DR. Regional cerebral blood flow during the Wisconsin Card Sorting Test in normal subjects studied by Xenon-133 dynamic SPECT: Comparison of absolute values, percent distribution values, and covariance analysis. Psychiatry Res Neuroimag 1993; $50: 177-92$.

31 Mesulam MM. A cortical network for directed attention and unilateral neglect. Ann Neurol 1981; 10 : 309-25.
32 National Institutes Of Mental Health 112 - CGI. Clinical Global Impressions. . In: Guy W, Bonato RR, Eds. Manual for the ECSEU Assessment Battery. Chevy Chase: NIH; 1979, pp. 12-16.

33 Neurosoft INC., Egan JP. New York: Academic Press; 1990.

34 Nuechterlein KH. Vigilance in schizophrenia and related disorders. In: Steinhauer SR, Gruzelier JH, Zubin J, Eds. Handbook of schizophrenia. Amsterdam: Elsevier; 1991. p. 397433.

35 Nuechterlein KH, Dawson ME. Information processing and attentional functioning in the developmental course of schizophrenic disorders. Schizophr Bull 1984; $10: 160-203$.

36 Oldfield RC. The assessment and analysis of handedness: The Edinburgh Inventory. Neuropsychologia 1971; 9 : 97-113.

37 Overall JE, Gorham DR. The Brief Psychiatric Rating Scale. Psychol Rep 1962; $10: 799-812$.

38 Pantalis C, Barnes TRE, Nelson HE. A pilot study of subcortical dementia in schizophrenia [abstract]. Schizophr Res 1989; 2 : 69.

39 Pantalis C, Barnes TRE, Nelson HE. Is the concept of frontalsubcortical dementia relevant to schizophrenia? Brit J Psychiatry 1992; $160: 442-60$.

40 Pantalis C, Nelson HE. Cognitive functioning and symptomatology in schizophrenia: The role of frontal-subcortical systems. In: David AS, Cutting JC, Eds. The neuropsychology of schizophrenia. Hove: Lawrence Earlbaum; 1994. p. 21529.

41 Raven JCADVANCES, Progressive MATRICES, Sets I, And II. Plan and use of the scale with a report of experimental work. London: Lewis HK; 1965.

42 Rosvold HE, Mirsky AF, Sarason I, Bransome ED Jr, Beck LH. A continuous performance test of brain damage. J Consult Clin Psychol 1956; $20: 343-50$.

43 Schröder J, Buchsbaum MS, Siegel BV, Geider FJ, Haier RJ, Lohr J et al Patterns of cortical activity in schizophrenia. Psychol Med 1994; 24 : 947-55.

44 Schröder J, Buchsbaum MS, Siegel BV, Geider FJ, Lohr J, Tang $C$ et al Cerebral metabolic activity correlates of subsyndromes in chronic schizophrenia. Schizophrenia Res 1996; 19: 41-53.

45 Siegel BJ Jr, Buchsbaum MS, Bunney WE, Gottschalk LA, Haier RJ, Lohr JB et al Cortical-striatal-thalamic circuits and brain glucose metabolic activity in 70 unmedicated male schizophrenic patients. Am J Psychiatry 1993; 150 : 1325-36.

46 Siegel BV Jr, Nuechterlein KH, Abel L, Wu JC, Buchsbaum MS. Glucose metabolic correlates of continuous performance test performance in adults with a history of infantile autism, schizophrenics and controls. Schizophr Res 1995; 17 : 85-94.

47 Talairach J, Tournoux P. Co-planar stereotaxic atlas of the human brain. Stuttgart: Thieme; 1988.

48 VanDen BOSCH, Rj Context and cognition in schizophrenia. . In: Van Den Boer JA, Westenberg HGM, Van Praag HM, Eds. Advances in the neurobiology of schizophrenia. Chichester: Wiley; 1995. p. 34366.

49 Volz HP, Gaser C, Häger F, Rzanny R, Mentzel HJ, Kreitschmann-Andermahr I et al Brain activation during cognitive stimulation with the Wisconsin Card Sorting Test - a functional MRI study on healthy volunteers and schizophrenics. Psychiatry Res Neuroimag 1997; 75 : 145-57.

50 Weinberger DR. Implications of normal brain development for the pathogenesis of schizophrenia. Arch Gen Psychiatry 1987; $44: 660-9$.

51 Woods SW. Regional cerebral blood flow imaging with SPECT in psychiatric disease: Focus on schizophrenia, anxiety disorders, and substance abuse. J Clin Psychiatry 1992; 53 suppl : $20-5$. 